\title{
THE SIZE OF MENTAL DEFECTIVE BOYS*
}

\author{
BY \\ GORDON DUTTON \\ From Botleys Park Hospital, Chertsey
}

(RECEIVED FOR PUBLICATION FEBRUARY 2, 1959)

It is often stated that mental defectives are physiologically inferior to the rest of the population (Penrose, 1949), and Tredgold (1952) states that the life history of many of them shows a defective vitality of both body and mind. Goddard (1912) showed that stature and weight could be positively correlated with intelligence. These impressions are borne out by a casual glance at the inmates of any mental defective hospital but it seems worth while to take a closer look at the physical size of mental defective children for not all of them show this depression of growth. Mongols are a group of defectives who are obviously inferior physically to their normal brethren as far as height is concerned. The group of children suffering from organic lesions of the brain, having hemiplegia or some other motor deficit, are not always smaller than normal and when one comes to consider the undifferentiated type of defect one meets with those who are normal in size and those who are smaller than normal for their life age.

The physical size and development of mongols have been dealt with elsewhere (Dutton, 1959). This paper is concerned with the heights, weights and skeletal development of other groups of mental defective children, those suffering from an undifferentiated type of defect or from an organic brain lesion.

The undifferentiated group comprises those cases showing mental defect without evidence of a neurological lesion, epilepsy, psychosis or any other symptom complex allowing of a more precise classification. This group divides into two further sub-groups, those who are normal in height for their age and those who are markedly shorter than they should be. These two groups have been termed: (1) Non-pathological, those whose physical size is normal for their age. (2) 'Metabolic', those whose height is depressed by more than a year of height age (Dutton, 1958).

* This paper has been abstracted from a thesis entitled 'The physical approach to amentia' accepted by London University for the M.D. degree.
There are therefore for consideration four groups of mentally defective children. (The group of psychotic children was too small to make possible any valid conclusions and has therefore been omitted. Similarly cases of known metabolic error have been excluded.)

The four groups are:

$\begin{array}{llll}\text { (a) Organic .. } & \ldots & \ldots & 31 \text { cases } \\ \text { (b) Non-pathological } & \ldots & 16 \text { cases. } \\ \text { (c) 'Metabolic' } & \ldots & \ldots & 22 \text { cases } \\ \text { (d) Mongols .. } & \ldots & \ldots & 50 \text { cases }\end{array}$

\section{Material and Methods}

All cases are considered to be mentally defective and are in the wards of a hospital specializing in the care of mental defectives.

The survey is confined to boys between the ages of 5 and 18 years. The bed allocation would not allow of sufficient girls for a worthwhile study.

Height. This was measured to the nearest $1 / 8$ inch using a conventional stadiometer in the Standard Erect Position of Krogman (1950).

Weight. This was measured to the nearest $\frac{1}{2} \mathrm{lb}$. nude apart from a pair of thin underpants, on a beam type of balance.

Skeletal Development. After considerable deliberation the inspectional method of Greulich and Pyle (1950) was selected since this is a well documented method that is economical and as only a single radiograph of the left wrist and hand is required it subjects the patient to the minimum amount of radiation. Each film was assessed on three separate occasions blind, and only after the mean of the three readings had been worked out was the name disclosed to the examiner.

Since skeletal development is expressed in years it was convenient to convert heights and weights into the same scale of measurement and this was done by reference to the tables of Sutcliffe and Canham (1950) which have been compiled from a 
cross-sectional survey of a sufficiently large number of English children in recent years to allow a satisfactory comparison.

It is also possible to use the developmental ages in the same way as the mental age and obtain a developmental quotient (Talbot, Sobel, Burke, Lindemann and Kaufman, 1947). These workers found that the following formulae gave satisfactory results:

$$
\begin{gathered}
\frac{\text { Height age }}{\text { Life age }} \times 100 ; \frac{\text { Weight age }}{\text { Life age }} \times 100 ; \\
\frac{\text { Skeletal age }}{\text { Life age }} \times 100 .
\end{gathered}
$$

The normal range for these methods is given as 80-120.

By using these formulae to obtain a developmental quotient it is possible to compare different age groups which would not be so easy if the raw figures alone were employed.

\section{Results}

Table 1 shows the means of the developmental quotients for height, weight and skeletal development in the four groups. This demonstrates that the mongols and the 'metabolic' group are similar as regards the depression of height and weight, whilst the other groups fall within the normal range. However here the similarity ends for it is only the 'metabolic' group that shows a significant depression in skeletal development.

TABLE 1

DEVELOPMENTAL QUOTIENTS FOR HEIGHT, WEIGHT AND SKELETAL DEVELOPMENT IN FOUR GROUPS OF MENTALLY DEFECTIVE BOYS

\begin{tabular}{c|c|c|c}
\hline Group & $\frac{\text { Height Age }}{\text { Life Age }} \times 100$ & $\frac{\text { Weight Age }}{\text { Life Age }} \times 100$ & $\frac{\text { Skeletal Age }}{\text { Life Age }} \times 100$ \\
\hline Organic .. & 86 & 92 & 95 \\
\hline $\begin{array}{r}\text { Non- } \\
\text { patho- } \\
\text { logical .. }\end{array}$ & 97 & 94 & 100 \\
\hline Metabolic' & 72 & 73 & 79 \\
\hline Mongols .. & 68 & 77 & 95 \\
\hline
\end{tabular}

The uniqueness of the 'metabolic' group is further shown by the fact that only $27 \cdot 3 \%$ of them have a skeletal development within plus or minus 2 S.D. from the mean and the rest of them, $72 \cdot 7 \%$, have a skeletal development depressed more than 2 S.D. below the mean. These figures are practically the reverse of those obtained when one considers all the other groups together for then $\mathbf{7 4 . 2} \%$ have normal skeletal development and only $25.8 \%$ have their skeletal development depressed more than 2 S.D. below the mean.

\section{Discussion}

Growth and development are inherent biological attributes and it is surprising how easily normal growth is taken for granted, so that it is only when it fails to come up to our expectations that we think about it.

In the present series, the mentally defective boys comprising two of the four groups failed to grow normally, and one of these proved unique in showing developmental failure as well. It is important to make this distinction between development and linear growth because the two are under different hormonal control.

In the mongol group it is a striking fact that whereas height and weight are retarded skeletal development is normal. In sharp contrast to this, the group termed 'metabolic' shows pronounced retardation in skeletal development. This group also shows height and weight reduction but it must be borne in mind that these patients were segregated from the non-pathological group on the grounds that height was depressed by more than one year of height age; that is to say, the distribution curve of height of the original undifferentiated group was divided into two. The patients forming the tail of this curve were separated off as the 'metabolic' group and the remainder formed the non-pathological group. Hence, the 'metabolic' group, by definition, consists of patients of retarded height age and similarly those of the non-pathological group are of normal height age. Moreover, in so far as weight is positively correlated with stature, it is to be expected that the method of classification determines the normal weight age of the nonpathological group and the reduced weight age of the 'metabolic' group.

The growth disorder of mongols has already been described in detail (Benda, 1949; Dutton, 1959). The 'metabolic' group, in addition to the features already described, shows characteristic biochemical anomalies. The members of it are immature as regards steroid excretion, urinary non-protein nitrogen excretion and the level of alkaline phosphatase, whereas patients comprising the nonpathological group are normal in these respects. The details of these biochemical investigations have been described elsewhere (Dutton, 1958).

It thus appears that the patients of the 'metabolic' group, originally segregated from the remaining patients investigated by the absence of any evidence of an organic pathology and by showing the common feature of depressed height age, are also characterized by retarded development and by 
biochemical anomalies. From the standpoint of chemical anthropology (Macy and Kelly, 1957) it may be said that the 'metabolic' group displays widespread biological inferiority involving physical, mental and biochemical immaturity.

It might be argued that the developmental anomalies are directly related to the reduced stature of whatever cause and must therefore characterize anyone selected on the criterion of reduced stature. If this is so, then any patients belonging to the organic group who happen also to be of reduced height age should show the same biochemical and skeletal peculiarities. This has not been found to be so, for patients of reduced stature belonging to the organic group are normal in these respects. It therefore seems justifiable to assume the existence of a distinct 'metabolic' group of patients characterized by retarded skeletal development, depressed height age and biochemical immaturity. A basic biochemical abnormality seems most likely to underlie such a widespread disturbance of growth and maturation.

The non-pathological group now appears as the residue of patients after separation of all those in the series distinguishable by specific and detectable abnormalities. They are not mongols or epileptics, have no clinically demonstrable organic symptoms and are normal in respect of growth and physical development.

Many of the non-pathological group may be normal variants of the lower end of the distribution curve of intelligence. Possibly some of them are cases of protophrenia (Bourne, 1955), a suggestion that receives some support from the investigations of Hermelin and Kirwan (1958), who concluded after a study of the case histories that the incidence of pathological homes was greater in the nonpathological type than in patients from the other groups.

\section{Summary}

The results of an investigation into the heights and weights of mental defective boys are given, with the results of an assessment of their skeletal maturity.

Cases of undifferentiated mental defect can be further subdivided on a basis of physical size and skeletal maturity.

My thanks are due to Dr. J. M. Crawford, Physician Superintendent at Botleys Park Hospital, for permission to undertake this study on his patients, to the nursing staff for their help, to Mr. P. Purkiss, the laboratory technician at Botleys Park and Mr. E. Comer of the same hospital who took the radiographs, and above all to the patients who have good naturedly submitted to the various examinations.

\footnotetext{
REFERENCES

Benda, C. E. (1949). Mongolism and Cretinism, 2nd ed. Grune and Stratton, New York.

Bourne, H. (1955). Lancet, 2, 1156

Dutton, G. (1958). M.D. Thesis. University of London.

(1959). Arch. Dis. Childh., 34, 46.

Goddard, H. H. (1912). J. nerv. ment. Dis., 39, 217.

Greulich, W. W. and Pyle, S. I. (1950). Radiographic Atlas of Skeletal Development of the Hand and Wrist. Stanford University Press, Stanford, California.

Hermelin, B. and Kirwan, E. (1958). Lancet, 2, 1013.

Krogman, W. M. (1950). A Handbook of the Measurement and Interpretation of Height and Weight in the Growing Child. Monogr. Soc. Res. Child. Develop., 13, No. 3.

Macy, I. G. and Kelly, H. J. (1957). Chemical Anthropology. University of Chicago Press.

Penrose, L. S. (1949). The Biology of Mental Defect. Sidgwick and Jackson, London.

Sutcliffe, A. and Canham, J. W. (1950). The Heights and Weights of Boys and Girls. Murray, London.

Talbot, N. B., Sobel, E. H., Burke, B. S., Lindemann, E. and Kaufman, S. B. (1947). New Engl. J. Med., 236, 783.

Tredgold, A. F. (1952). A Textbook of Mental Deficiency, 8th ed. Baillière, Tindal and Cox, London.
} 